\title{
Mulher e Água: a vida como denominador comum
}

Dossier ÁGUA E MULHER

\section{Consuelo Yatsuda Moromizato Yoshida}

Doutora e professora da PUC-SP e UNISAL-Lorena; Desembargadora Federal - TRF 3 a Região. Revisão, formatação e adequação às normas da ABNT: Ana Clara Aben-Athar Barcessat, advogada, Mestre em Direitos Difusos e Coletivos pela PUC-SP. São Paulo [SP] Brasil. <cyoshida@trf3.jus.br>

\section{Resumo}

Existe uma relação intrínseca entre a mulher e água, diversas abordagens podem defini-la, entretanto este texto pretende abordar a presença da água no corpo da mulher para gerar a vida e sustentá-la nos primeiros meses.

\section{Palavras-chave}

Gestação. Líquido amniótico. Leite materno.

\section{Woman and Water: the life as common denominator}

\begin{abstract}
There is an intrinsic relationship between the woman and water, several approaches can define it, however this text intends to address the presence of water in the woman's body to generate life and sustain it in the first months.
\end{abstract}

\section{Keywords}

Gestation. Amniotic fluid. Breast milk. 


\section{Introdução}

A celebração, no mês de março, do Dia Internacional da Mulher e do Dia Mundial da Água é muito significativa. Há uma relação muito intrínseca entre mulher e água, que inspirou inclusive o tema central desta publicação.

A relação da mulher com a água pode ser vista sob diferentes enfoques, tanto no âmbito social e político, como a escassez de água em determinados lugares que obrigam muitas pessoas, e em sua maioria, mulheres, a se deslocarem de suas casas e irem buscar água potável para a sobrevivência de sua família, como também há em âmbito interno e pessoal, numa relação mais biológica e até poética: tanto a mulher como a água são necessárias para a vida humana.

Neste artigo, elegendo a vida como denominador comum à mulher e à água, serão abordados dois líquidos vitais que possibilitam a mulher exercer o dom gratuito da procriação e da perpetuação da espécie humana: o líquido amniótico e o leite materno; tanto um quanto outros compostos basicamente de água.

\section{Mulher, água e vida}

O denominador comum mais lembrado entre a mulher e a água é a vida. A água é o elemento mais essencial para a vida, e a mulher é a geradora da vida, de seu ventre brota a vida.

Nesta oportunidade, escolhemos abordar duas substâncias vitais, que tem a água como elemento fundamental: o líquido amniótico e o leite materno, para maior conhecimento e valorização da contribuição inigualável da mulher para geração de uma nova vida do seu ventre e para a vida saudável da criança amamentada com o leite materno nos primeiros meses e anos de vida.

Desde o início da emancipação feminina, com a liberdade sexual advinda, num primeiro momento, das pílulas anticoncepcionais e a integração da mulher no mercado de trabalho, a sociedade moderna tem imposto novos padrões de vida às mulheres. Boa parte da sociedade passou a aceitar, liberalizar e legalizar a prática do aborto, além das hipóteses legais, o que antigamente era impensável. Além disso, por várias circunstâncias o aleitamento materno deixou de ser prioridade em períodos fundamentais da vida do bebê.

\section{A mulher e o líquido vital da gestação: o líquido amniótico}

É de conhecimento geral que o líquido amniótico desempenha papel de grande importância no desenvolver da gestação, por propiciar diversos benefícios fetais. Há diversos estudos e pesquisas científicas nas áreas da saúde sobre o líquido amniótico, com informações técnicas minudentes, que escapam aos propósitos deste trabalho.

Entretanto, é importante mencionar que o líquido amniótico tem função de amortizar o ambiente fetal contra traumas, e suas propriedades antibacterianas. Soma-se a isso o fato de um volume satisfatório de líquido amniótico ser necessário para a movimentação fetal e, assim, um adequado desenvolvimento do sistema musculoesquelético, gastrointestinal e pulmonar (Dertkigil et al., 2005).

\subsection{0 líquido amniótico e sua importância na gestação}

É por volta do $12^{\circ}$ mês da concepção que o líquido amniótico vai se formando, sendo produzido, no início, na placenta e com água do corpo da mãe. A partir do 4⿳o mês da gravidez (por volta da $20^{\text {a }}$ semana) os rins do bebê começam a funcionar e tomam a seu cargo a produção do líquido amniótico que passa a ser constituído, sobretudo, por urina fetal1.

Sendo assim, é possível dizer que o líquido amniótico é o fluido que envolve o embrião e depois o feto durante a gestação. Ele está contido no saco amniótico e é composto essencialmente de água

${ }^{1}$ Líquido amniótico - Definição. Disponível em: <https://saude.ccm.net/faq/1359-liquido-amniotico-definicao>. 
e secreções do feto, especialmente renais (sua urina) e células vindas do feto do saco amniótico. Enquanto está no útero, o bebê flutua nesse líquido apenas suspenso pelo cordão umbilical. Além de funcionar como um escudo protetor contra infecções, ao mesmo tempo em que fornece fluidos, nutrientes, também permite o desenvolvimento regular dos pulmões do bebê.

Estudos na área apontam que a quantidade de líquido amniótico é maior em cerca de 34 semanas de gestação, quando atinge uma média de $800 \mathrm{ml}$. Já próximo às 40 semanas de gestação, aproximadamente $600 \mathrm{ml}$ de líquido amniótico cercam o bebê (Silva, n.d.).

Este líquido amniótico circula constantemente durante a gestação, sendo "engolido" e "inalado" pelo feto, eliminando depois pelas fezes e urina. Assim, o líquido auxilia não só a expansão e desenvolvimento pulmonar, como também permite regular o funcionamento do tubo digestivo.

\subsection{A importância do controle do volume}

É importante que haja um volume satisfatório de líquido amniótico, tanto para a movimentação fetal como para um adequado desenvolvimento do dos sistemas musculoesquelético, gastrointestinal e pulmonar, evitando assim a formação de bridas e as malformações fetais consequentes.

No passado, o acesso a alguma avaliação do líquido amniótico era feito de maneira indireta, através da palpação abdominal e medida da altura uterina, ou através de punção da cavidade amniótica e nas histerotomias durante o parto.

Com o advento da ultrassonografia, tal acesso tornou-se mais fácil e não invasivo. Não tardou a aparecerem normatizações para aferição do volume amniótico.

Adotam-se comumente como valores normais para a população brasileira, os índices de $80 \mathrm{~mm}$ a $180 \mathrm{~mm}$ em qualquer idade gestacional. Essa representa a rotina da maior parte dos serviços, embora já se saiba que o ILA varia em função da idade gestacional e que, portanto, deveriam ser adotados valores de referência para cada idade gestacional. Dados destes estudos indicam que o LA aumenta drasticamente de $30 \mathrm{ml}$ na 10 a semana, para $250 \mathrm{ml}$ na 16 a semana e para aproximadamente $500 \mathrm{ml}$ na 20 a semana (aumentando em torno de $10 \mathrm{ml} /$ dia). $\mathrm{Na} 28 \mathrm{a}$ semana tem volume aproximado de $800 \mathrm{ml}$, atingindo um platô quando alcança $1000-1100 \mathrm{ml}$, com 34 semanas.8 A partir do termo, o LA decresce, retornando para $700-800 \mathrm{ml}$ ao nascimento e, em gestações prolongadas, o LA chega ainda a diminuir cerca de $33 \%$ por semana. A avaliação feita através do parto fornecia apenas uma medida do LA e não predizia informações neonatais de modo a poder tratar gestantes de risco (Dertkigil et al., 2005).

Várias curvas de normalidade foram desenhadas para as mais diversas populações. A importância de se determinar os valores de normalidade para cada idade gestacional está calcada na avaliação mais fidedigna de gestantes, anteriormente categorizadas como patológicas, o que possivelmente mantêm ILA normal, evitando-se assim erros na conduta obstétrica. A avaliação do líquido amniótico sempre foi preocupação na prática obstétrica por refletir o bem-estar fetal.

\subsection{Técnicas para correção das alterações de volume amniótico}

Mais recentemente, pesquisadores têm tentado diversas técnicas na correção dos distúrbios de volume amniótico (aumento ou diminuição), na tentativa de diminuir a morbidade associadas a esses distúrbios. As técnicas empregadas são frequentemente invasivas, como a amniocentese e a amnioinfusão.

Um método considerado não invasivo, por não acessar a cavidade amniótica diretamente, é a hiperhidratação materna por via oral ou endovenosa.

Em que pese ser essa técnica muito utilizada no Brasil, os estudos existentes são apenas relatos de série de casos, carecendo de estudos controlados e randomizados para que haja consenso sobre a efetividade na utilização do método, com resultados estatisticamente comprovados. 


\subsection{Atividade física em água na gestação}

Até pouco tempo atrás se acreditava que mulheres gestantes não deveriam fazer exercícios físicos pelo potencial risco de complicações para a mãe e para o feto. Atualmente essa é uma recomendação que deve ser analisada caso a caso, em virtude das particularidades de cada gestação, porém, em geral, a prática de exercícios físicos para as grávidas não só é permitido, como recomendável.

Dentre os benefícios da atividade física na gestação estão a sensação de bem estar e melhora do cansaço, da qualidade do sono e das dores nas costas, melhor controle de peso com menor ganho e melhor controle glicêmico em gestantes diabéticas.

A prática de atividade física em água vem sendo cada vez mais recomendada e utilizada de forma cultural e empírica pelas gestantes ao longo dos últimos anos. Entretanto, vários fatores foram alvos de preconceito na imersão em gestantes. Um deles diz respeito ao tabu da contaminação uterina através da entrada de fluidos pela vagina.

Ainda são escassos os estudos relativos à prática da atividade física moderada na água para gestantes e seus benefícios maternos e fetais. A importância de pesquisas como essas seria a de aprofundar os conhecimentos acerca dos exercícios aeróbicos sob imersão de gestantes em água, principalmente no que diz respeito ao volume de líquido amniótico e bem estar fetal durante a gestação. Isso possibilitaria um melhor entendimento das alterações fisiológicas do volume do líquido amniótico causadas pela prática de imersão da gestante em água, quando submetidas à atividade física moderada sob a forma de hidroginástica, suas vantagens, desvantagens e/ou ganhos secundários.

É possível que a prática demonstre aumentar significativamente o volume de líquido amniótico, sem prejuízo fetal, e, assim, poderá talvez ser utilizada como uma técnica não invasiva de aumento do volume de líquido, quando alguma situação clínica obstétrica assim necessitar.

\section{A mulher e o aleitamento materno}

Após o nascimento do bebê, sobrevém a fase igualmente fundamental do aleitamento materno, pela própria mãe, ou fornecido pelos bancos de leite.

\subsection{A importância do leite materno nos primeiros meses e anos de vida da criança}

O leite materno possui características bioquímicas ideais para o crescimento e desenvolvimento da criança. Por meio dele, o bebê recebe o aporte necessário para um bom desenvolvimento, sendo uma prática saudável tanto para mãe quanto para o filho. Além disso, protege contra infecções, doenças respiratórias, doenças crônicas não transmissíveis e má-formação da arcada dentária. A amamentação também é uma possível estratégia na prevenção da obesidade infantil e de certas patologias (Gargiulo, 2017).

O leite materno é capaz de prover isoladamente todos os nutrientes que uma criança necessita nos primeiros seis meses de vida para crescer com saúde, por isso é chamado de um alimento completo. A amamentação favorece também o vínculo mãe-filho e facilita o desenvolvimento emocional, cognitivo e do sistema nervoso.

O leite materno é capaz de suprir sozinho as necessidades nutricionais da criança nos primeiros seis meses e continua sendo uma importante fonte de nutrientes no segundo ano de vida ou mais, especialmente de proteínas, gorduras e vitaminas.

A partir do sexto mês, as crianças podem precisar de uma alimentação variada, mas recomendase que o aleitamento materno continue sendo oferecido até o segundo ano de vida ou mais. A mãe pode continuar a amamentar até quando ela e a criança desejarem. A avaliação da interrupção da amamentação na maioria das vezes envolve aspectos sociais e psicológicos da mãe e criança. 


\subsection{Composição nutricional do leite materno}

A composição nutricional do leite materno diferencia-se ao longo da mamada e da idade da criança.

Ao analisar-se a composição do leite humano, distingue-se nele o colostro, o leite de transição e o leite maduro. Também ocorre uma diferença na composição do leite nas distintas etapas da amamentação, nas diferentes horas do dia e até nas fases da mesma mamada, do começo ao término.

O colostro é produzido aproximadamente nos cinco primeiros dias pós-parto e é muito rico em proteínas, vitaminas, sais minerais, macrófagos (que conferem proteção ao recém-nascido) além da lactose.

Aproximadamente entre o quinto e o décimo quinto dia após o nascimento o leite de transição é produzido. Sua composição altera-se ao longo dos dias, variando das características do colostro às do leite maduro.

Já o leite maduro possui maior valor calórico e maior volume. É constituído principalmente de proteínas, carboidratos, lipídios, minerais e vitaminas.

Antes de tudo, para uma amamentação bem sucedida, a mãe necessita de constante incentivo e suporte dos profissionais de saúde, da família e da comunidade em geral. Recomenda-se que as mães adotem hábitos alimentares saudáveis e alimentação adequada durante a lactação, como: consumir dieta variada, incluindo pães e cereais, frutas, legumes, verduras, derivados do leite, carnes e ingestão de água de acordo com as condições econômicas de cada família. Geralmente, as mulheres que amamentam não precisam evitar determinados alimentos.

É importante ressaltar que o volume de leite produzido varia, dependendo de quanto a criança mama e da frequência com que o faz. Tal frequência deve ser guiada pela vontade da criança. Quanto mais volume de leite e mais vezes a criança mamar, maior será a produção de leite.

\subsection{Semana Mundial do Aleitamento Materno}

Entre os dias $1^{\text {o } ~} 7$ de agosto é celebrada a Semana Mundial de Aleitamento Materno. A data, celebrada em mais de 150 países, teve como tema em 2017 "Trabalhar juntos para o bem comum", com o objetivo de retomar a importância do trabalho em conjunto e enaltecer a relevância da sustentabilidade para o desenvolvimento da sociedade.

\subsection{Campanhas de doação do leite materno no Brasil}

O "Dia Nacional de Doação de Leite Humano" é um momento especial de sensibilização da sociedade para a importância da doação de leite humano, principalmente pra para os Bancos de Leite Humano do Brasil. Assim como, é uma iniciativa a mais para a proteção e promoção do aleitamento materno.

Dentre os objetivos da campanha estão a estimulação da doação de leite materno, promoção de debates sobre a importância do aleitamento materno e da doação de leite humano e a divulgação dos bancos de leite nos Estados e nos Municípios.

A Lei no 13.227, de 28 de dezembro de 2015, institui o "Dia Nacional de Doação de Leite Humano" a ser comemorado, anualmente, no dia 19 de maio, e a "Semana Nacional de Doação de Leite Humano", a ser comemorada, anualmente, na semana que incluir o dia 19 de maio.

A primeira comemoração do Dia Nacional de Doação de Leite Humano foi realizada no ano de 2004. Em todos os anos o Ministério da Saúde produz e distribui material de divulgação com a finalidade de mobilizar as mulheres de todo o país sobre a importância do leite materno para aqueles bebês (em especial, prematuros e recém-nascidos de baixo peso internados em UTI neonatal) que não têm a oportunidade de serem amamentados por suas mães. 
No Brasil, anualmente, o número de mulheres que dedicam seu tempo para retirar o leite para doação ultrapassa 115 mil. Por ano, são recolhidos cerca de 150 mil litros de leite materno, que passam pelo processo de pasteurização e controle de qualidade antes de chegarem a mais de 135 mil recém-nascidos. De acordo com o Ministério da Saúde, este volume representa de $55 \%$ a $60 \%$ da demanda de leite humano no país (Ministério da Saúde do Brasil, 2017).

Esses dados mostram que o Brasil tem a maior e mais complexa rede de bancos de leite do mundo, com 221 unidades e 186 postos de coleta, segundo o Ministério da Saúde. Apesar da estrutura e das mobilizações, o número de doações ainda é baixo, e a Rede Brasileira de Bancos de Leite Humano consegue suprir aproximadamente $60 \%$ da demanda para os recém-nascidos prematuros e de baixo peso internados em Unidades de Terapia Intensiva (UTIs) neonatais do país.

Todo ano nascem em média aproximadamente 3 milhões de bebês no país, e $14 \%$ deles são prematuros ou têm baixo peso (menos que 2,5 quilos). A amamentação é o principal fator de redução da mortalidade infantil, pois diminui a ocorrência de diarreias e infecções, principais causas de morte em recém-nascidos. Estima-se que o aleitamento materno reduza em até $13 \%$ a morte de crianças menores de 5 anos por causas preveníveis.

Desenvolvida há 32 anos, a estratégia de bancos de leite beneficiou, entre 2009 e 2016, mais de 1,8 milhão de recém-nascidos e teve apoio de 1,3 milhão de doadoras (Rede Global de Bancos de Leite Humano, n.d.).

Além disso, o Brasil tem acordos de cooperação e exporta técnicas de baixo custo utilizadas na implantação de bancos de leite em 24 países. Segundo o Ministério da Saúde, em 2001, a Organização Mundial da Saúde reconheceu a Rede Brasileira de Bancos de Leite Humano como uma das ações que mais contribuíram para a redução da mortalidade infantil no mundo na década de 1990. De 1990 a 2012, a taxa de mortalidade infantil no Brasil caiu 70,5\% (Ministério da Saúde do Brasil, 2017).

A doação de leite humano também representa uma economia de cerca de $\mathrm{R} \$ 180$ milhões com a diminuição da necessidade de compra de fórmulas artificiais nas maternidades do Sistema Único de Saúde (SUS) (Verdélio, 2017).

\section{Conclusão}

A natureza dotou a mulher do poder da procriação, tornando-a partícipe do processo de perpetuação da espécie humana. Aparelhou seu corpo das condições, estruturas e funções para o desempenho deste nobre mister, incluindo o aleitamento, essencial nos primeiros meses e anos de vida do bebê.

E nesse processo, como se demonstrou, a água ingressa nas diferentes fases como elemento vital, possibilitando a mulher cumprir os desígnios que a natureza lhe reservou.

O embrião e o feto se desenvolvem no meio líquido, envoltos pelo líquido amniótico, com múltiplas funções vitais. Para se manter níveis adequados desse líquido, são utilizadas como terapias não invasivas a hidratação e o exercício físico na água. E o primeiro e mais completo alimento do bebê é o leite materno, em que a água é o componente básico.

\section{Referências}

Dertkigil, M. S. J., Cecatti, J. G., Cavalcante, S. R., Baciuk, E. P., \& Bernardo, A. L. A. (2005). Líquido amniótico, atividade física e imersão em água na gestação. Departamento de Tocoginecologia. Rev. Bras. Saúde Matern. Infant., Recife, 5 (4): 403-410, out. / dez. Recuperado de: <http://www.scielo.br/pdf/rbsmi/ v5n4/27758.pdf>. Acesso em 16 mai. 2018.

Gargiulo, P.(2017) Saúde Entrevista: Importância do leite materno como fonte de alimento para o bebê. Recuperado de: <http://blog.saude.mg.gov.br/2017/07/31/saudeentrevista-importancia-do-leitematerno-como-fonte-de-alimento-para-o-bebe/>. 
Líquido amniótico - definição.

Recuperado de: <https://saude.ccm.net/faq/1359-liquido-amniotico-definicao>.

Ministério da Saúde do Brasil. (2017). Aleitamento Materno. Ministério da Saúde do Brasil. Recuperado de: $<$ http://portalms.saude.gov.br/saude-para-voce/saude-da-crianca/aleitamento-materno>.

Rede Global de Bancos de Leite Humano (n.d.) Recuperado de: <https://rblh.fiocruz.br/pagina-inicialrede-blh>.

Silva, C. (n.d.) Função do líquido amniótico que envolve o bebê é mais importante do que parece. Recuperado de: < https://www.vix.com/pt/maes-e-bebes/550555/funcao-do-liquido-amniotico-que-envolve-o-bebe-emais-importante-do-que-parece>.

Verdélio, A. (2017). Com maior rede de leite materno do mundo, Brasil ainda precisa de doadoras. Recuperado de: <http://agenciabrasil.ebc.com.br/geral/noticia/2017-05/rede-de-doacao-de-leitematerno-do-brasil-atende-60-da-demanda>. 